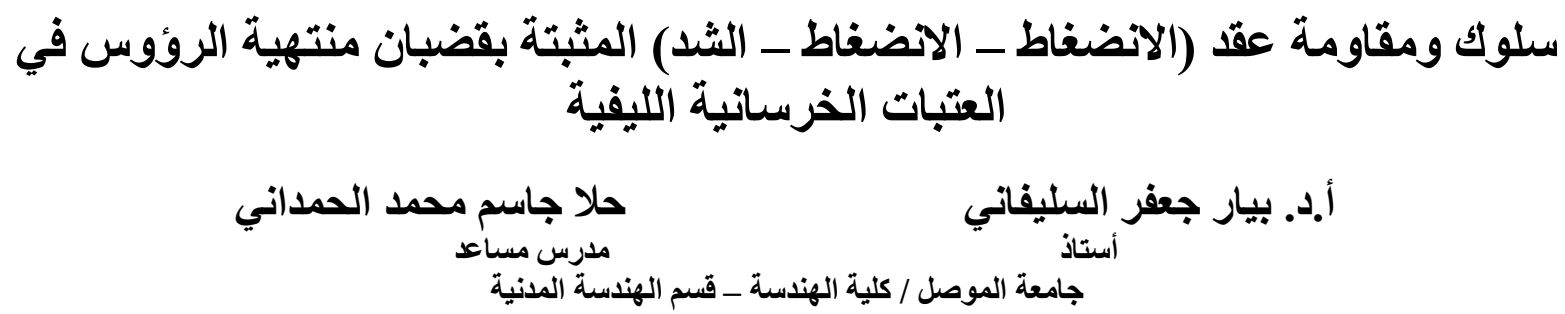

الخلاصة

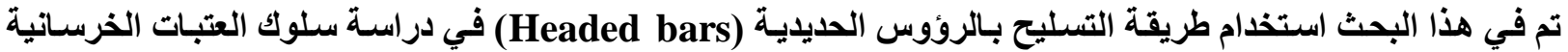

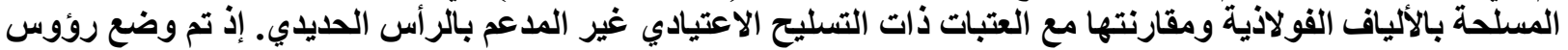

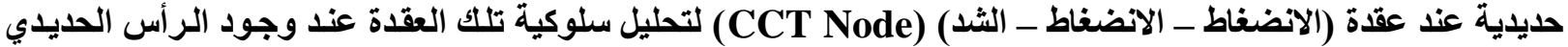

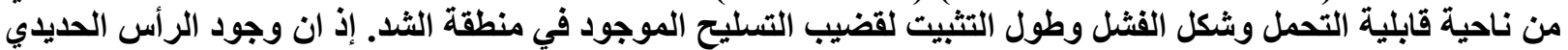

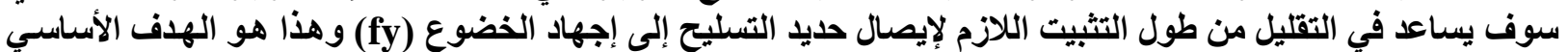

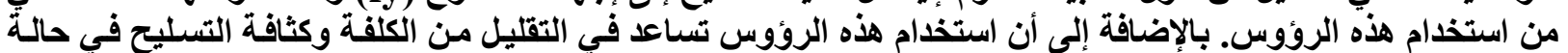

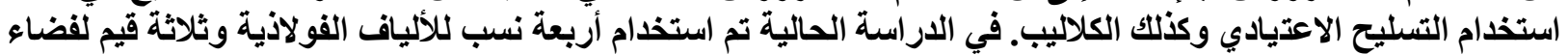

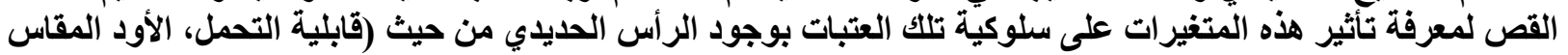

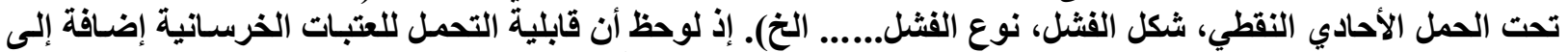

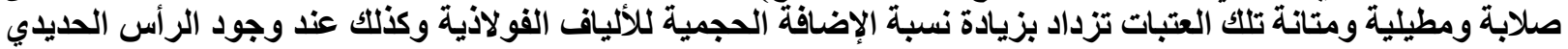

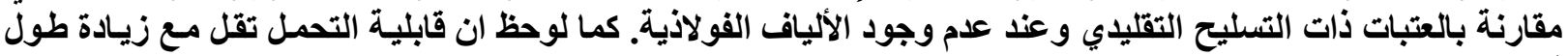

فضاء القص.

\title{
Behavior and Capacity of CCT Nodes Anchored By Headed Bars in Fibrous Concrete Beams
}

\section{Dr. Bayar J. Al-Sulayfani}

Professor

\section{Hala Jassim AL Hamdany}

Assistant Lecturer

\begin{abstract}
In the current research, the method of reinforcing by means of "Headed Bars" reinforcement was utilized in order to study the behavior of fiber reinforced beams, then conducting a comparison study with conventionally reinforced beams without "headed bar", where by headed bars were placed at the CCT node to analyze the behavior of the node. The presence of the headed bar with regard to bearing capacity, failure mode, and anchorage length for the reinforcing bar at the tension zone. Where the presence of the headed bar will help in reducing the anchorage length necessary to bring the reinforcing steel to yield stress (fy).This is the main objective of using such head bar reinforcing. In addition the use of this reinforce enables in the reduction of cost and the congestion of reinforce as well as the hooks. Four ratios of steel fiber and three values of shear span were used in order to find out the effect of those variables on the behavior of beams with headed bars reinforce regarding :bearing capacity, deflection under single point load, shape and type of failure,....etc. It was noticed that the bearing capacity, stiffness and ductility increased with the increased of volumetric steel fiber addition, also in the presence of headed bars reinforcement when compared with conventionally reinforced beams without steel fibers. The bearing capacity reduced as the shear span length increased.
\end{abstract}


عند تصميم الأعضـاء الخرسـانية بطريقة المقاومـة تُعتمد مقاو مـة الخضوع (fy) لحديد التسليح كإجهاد في التصميم

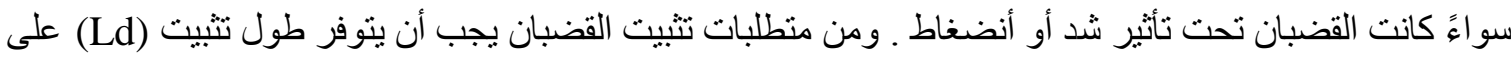

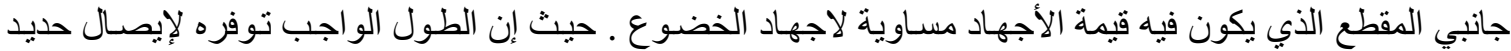

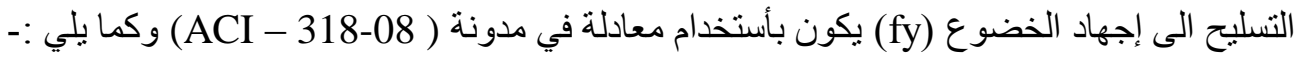

$\frac{L_{d}}{d_{b}}=\frac{9}{10} \frac{f_{y}}{\lambda \sqrt{f_{c^{\prime}}}} \frac{\Psi_{t} \cdot \Psi_{e} \cdot \Psi_{s}}{\frac{C_{b}+K_{t r}}{d_{b}}}$

$(\mathrm{Ld} \geq 300 \mathrm{~mm})$

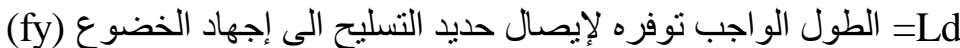

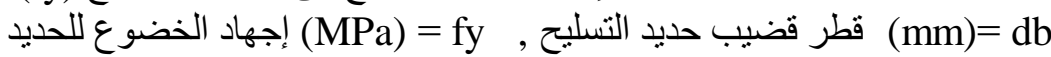
مقاومة الانضغاط للخرسانة. بو ${ }_{t}$ معامل يؤخذ (1.3) إذا كان سمك الخرسانة تحت حديد التسليح الأفقي لاتقل عن (300mm) وفيما عدا ذلك

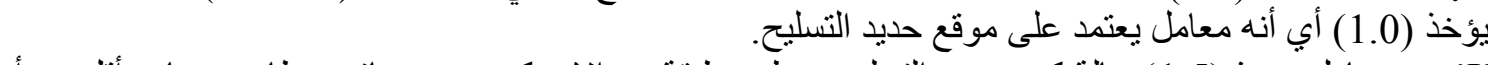

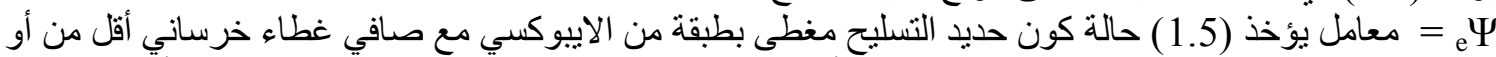

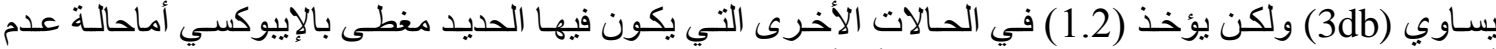
أحتو اءه الإييوكسي فيؤخذ في هذه الحالة (1.0) أبي أنه معامل يعتمد على حالة كون حديد التسليح مغطى بالإيبوكسي الإيوي

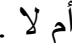
T = معامل يؤخذ (0.8) حالة أستخدام أقطار قضبان مساوية أو أقل من (19mm) وفيما عدا ذلك فيؤخذ(1.0) أي أنه يعتمد على قطر قضبان التسليح .

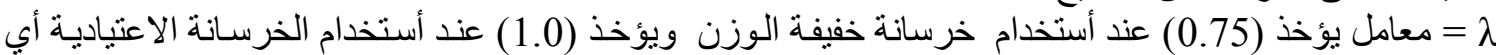

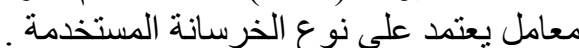
Cb . (mm) Ktr=معامل التسليح المستعرض يتم حسابه بأستخدام المعادلة التالية:-

$$
K_{t r}=\frac{40 . A_{t r}}{s . n}
$$

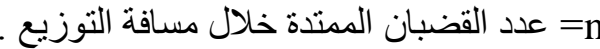

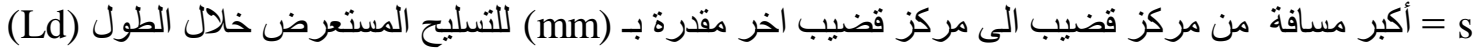

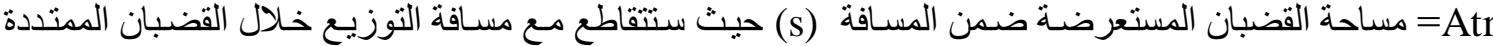
[1].$\left(\mathrm{mm}^{2}\right)$

ففي بعض المو اقع لايمكن توفير هذا الطول خاصـة في النهايات غير المستمرة للأعضـاء الأنشـائية كما في حالـة

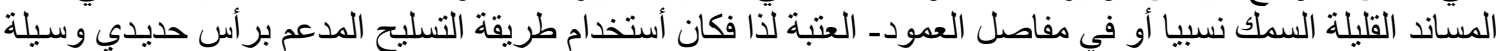

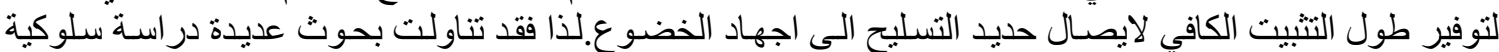

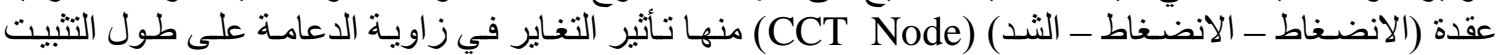

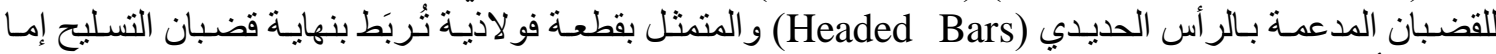

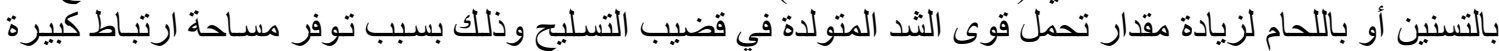

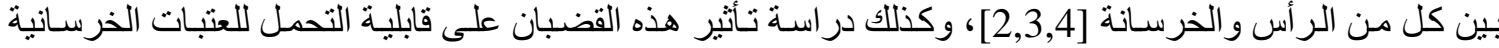

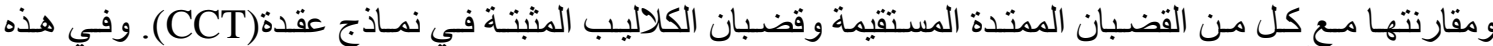

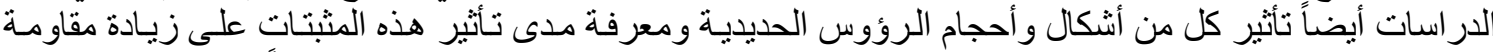

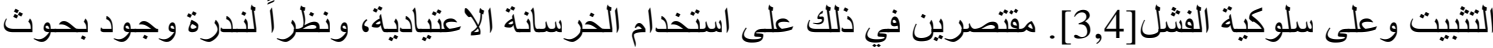

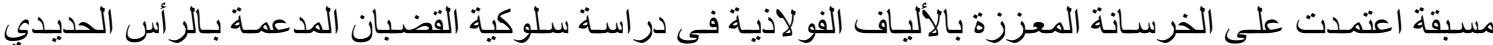

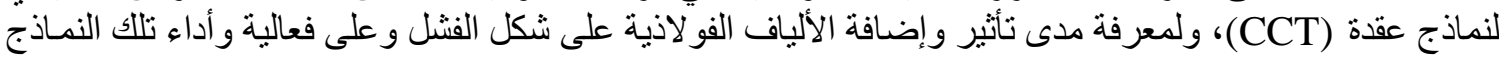




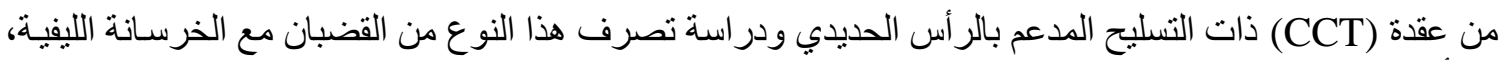

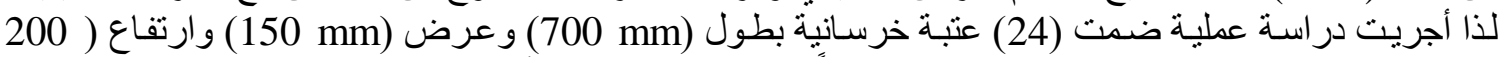

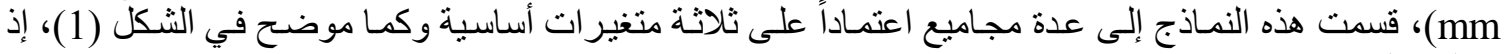
شملت كل من أن إن

1- التسليح الاعتيادي (Non Headed Bar) و التسليح المدعم بالر أس الحديدي (Headed Bars).

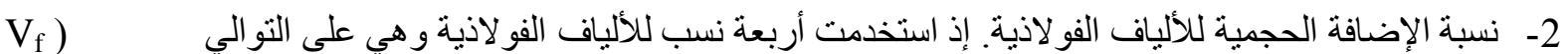

$$
(=0.0,0.5,1.0,1.5 \%
$$

3- المسافة الأفقية (طول فضاء القص) من نقطة الحمل المسلط إلى مركز الإسناد. إذ استخدمت ثنلاث قيم لفضـاء القص

وهي على التو الي (av=150, 200, 250 mm).

يهذف هذا البحث إلى إعطاء صورة واضحة عن اعتماد الخرسانة المعززة بالألياف الفو لاذية وعن اعتمـاد الر أس الحديدي في تحسين أداء هذه الأعضاء الإنشائية.

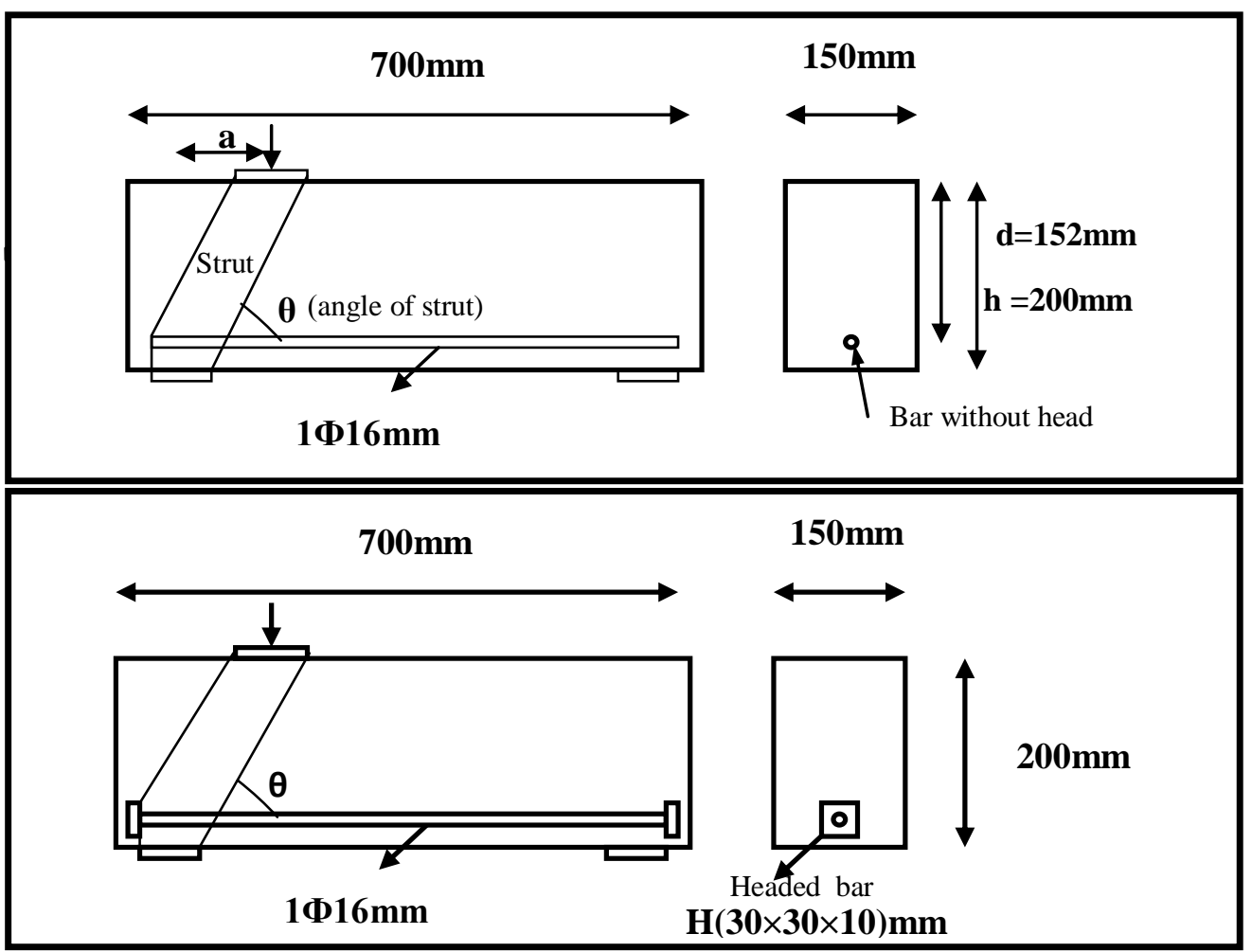

الشكل (1): يوضح تفاصيل العتبة الخرسانية المستخدمة في البحث

2. 2 - 2. 2 المواد المستخدمة

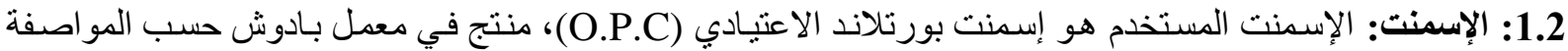
القياسية العر اقية (IQS No5) لسنة (1984) [5] و الخو اص الميكانيكية والفيزياوية للإسمنت مذكورة في الجدولين (1) و

2.2: 2.2: الماء: استخدام ماء الثرب الاعنبادي الخالي من الشو ائب.

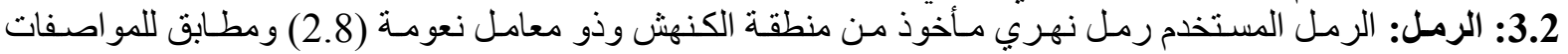
البريطانية (6,76 882:1992]، بالنسبة للتندرج و التحليل المنخلي للرمل المستعمل موضح في الجدول (3) 4.2: الحصى: نم استخدام الحصى النهري المحلي المدور بمقياس أقصى للركام (14mm) ونتائج التحليل المنخلي وتدرج

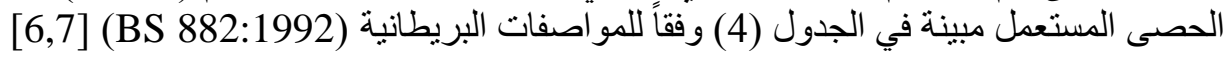




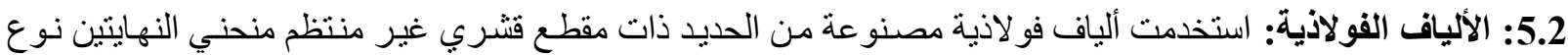

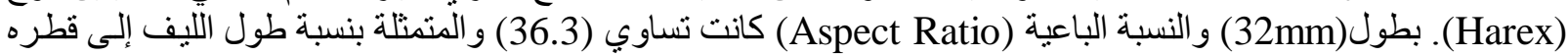
المكافئ

6.2 المواد المضافة

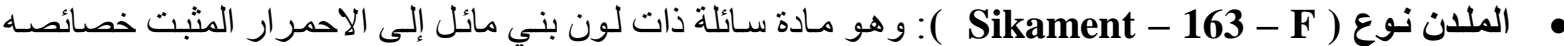

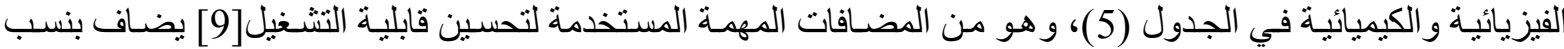

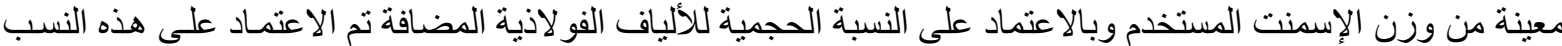
بوصفها تعطي مقدار هطول ثابت والبالغ (100mm) ولكل أنواع الخرسانة المستخدمة في هذا البحث و التي شملت : 1 - إضافة (0.2\%) من وزن الاسمنت إلى الخلطة الخرسانية حالة استخدام( 2- إضافة (0.45\% ) من وزن الاسمنت إلى الخلطة الخرسانية حالة استخدام (0. 3- إضافة (0.95\% ) من وزن الاسمنت إلى الخلطة الخرسانية حالة استخدام (

الجدول (1 ): يوضح التحليل الكيميائي للإسمنت المستخدم ومركباته الرئيسة [5]

\begin{tabular}{|c|c|c|}
\hline حدود المواصفة (IQS:5/1984)(\%) & النسبة المئوية (\%) & اكاسيد عناصر الاسمنت \\
\hline $3-8$ & 5.6 & أوكسيد الألمنيوم \\
\hline $17-25$ & 21.52 & أوكسيد السليكا \\
\hline $0.5-6$ & 2.74 & أوكسيد الحديد \\
\hline $60-67$ & 62.55 & أوكسيد الكالسيوم CaO \\
\hline لا يزيد عن \% & 2.54 & ثلاثي أوكسيد الكبريت \\
\hline لا يزيد عن 5\% & 3.23 & أوكسيد المغنيسيوم MgO \\
\hline & & مركبات الاسمنت الرئيسية \\
\hline $31.03-41.05$ & 36.44 & ثلاثي سليكات الكالسيوم C \\
\hline $28.61-37.9$ & 34.20 & ثنائي سليكات الكالسيوم C \\
\hline $11.96-12.3$ & 12.07 & ثلاثي ألومينات الكالسيوم C \\
\hline $7.72-8.02$ & 7.98 & رباعي ألومينات الكالسيوم الحديدية C \\
\hline
\end{tabular}

الجدول (2): يوضح التحليل الفيزيائي للإسمنت المستخدم [5].

\begin{tabular}{|c|c|c|}
\hline 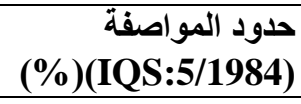 & نتيجة الفحص & 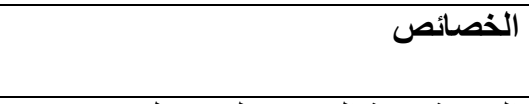 \\
\hline لا تزيد عن \% 10 ل & $\% 2$ & النعومة(نسبة المتبقي على منذل رقم 170) \\
\hline \multicolumn{3}{|r|}{ وقت التماسك } \\
\hline لا تقل عن 45 دقيقة & 135 & الابتدائي (دقيقة) \\
\hline لا تزيد عن 600 دقيقة & 375 & النهائي (دقيقة) \\
\hline \multicolumn{3}{|r|}{ مقاومةً الانضغاط (MPa) } \\
\hline لا تقل عن (16 MPa) & 18.42 & 3 \\
\hline لا تقل عن (24 MPa) & 26.84 & 7 \\
\hline \multicolumn{3}{|r|}{ مقاومة الثد (MPa) } \\
\hline لا تقل عن(1.6 MPa) & 1.78 & 3 \\
\hline لا تقل عن (2.4 MPa) & 2.5 & 7 \\
\hline
\end{tabular}


ألسليفاني: سلوك ومقاومة عقد (الانضغاط ـ الانضغاط ـ الثد) المثبتة بقضبان منتهية الروؤس في العتبات

الجدول (3) : يوضح التحليل المنظلي للركام الناعم المستخدم مع حدود المواصفات القياسية البريطانية .[7] (BS 882:1992)

\begin{tabular}{|c|c|c|c|}
\hline مقياس المنخل & \% الحد العام & \% الرمل المار & \% حدود الرمل المتوسط القياسية \\
\hline $4.75(\mathrm{~mm})$ & $89-100$ & 100 & -------- \\
\hline $2.36(\mathrm{~mm})$ & $60-100$ & 89.2 & $65-100$ \\
\hline $1.18(\mathrm{~mm})$ & $30-100$ & 68.4 & $45-100$ \\
\hline $600(\mu \mathrm{m})$ & $15-100$ & 45.7 & $25-80$ \\
\hline $300(\mu \mathrm{m})$ & $5-70$ & 14.8 & $5-48$ \\
\hline $150(\mu \mathrm{m})$ & $0-15$ & 3.8 & -------- \\
\hline
\end{tabular}

الجدول(4): يوضح التحليل المنظلي للركام الخثن المستخدم مع حدود المواصفات القياسية البريطانية .[7] (BS 882:1992)

\begin{tabular}{|c|c|c|}
\hline مقاس المنخل (mm) & \% النسبة المارة & \% الحدود القياسية المارة \\
\hline 20 & 100 & 100 \\
\hline 14 & 91 & $90-100$ \\
\hline 10 & 53.4 & $50-85$ \\
\hline 5 & 0 & $0-10$ \\
\hline
\end{tabular}

\begin{tabular}{|c|c|}
\hline Sikament-163-F & اسم الملدن \\
\hline بن بني غامق & اللون \\
\hline $1.2 \mathrm{~kg} / \mathrm{l}$ & الكثافة \\
\hline سائل & الحالة الفيزيائية \\
\hline 0.6-2.5\% (من وزن الإسمنت) & الجر عة القياسية \\
\hline $10 \pm 1.0$ & قيمة (pH) \\
\hline
\end{tabular}

7.2: حديد التسليح: استخدم نو عين من التسليح شمل النوع الأول التسليح الاعنيادي المتمثل باستخدام قضيب تسليح منفرد

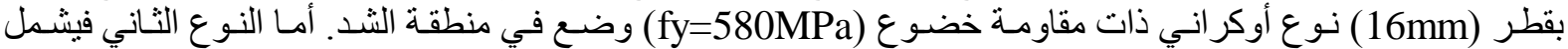

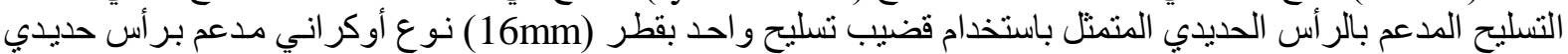

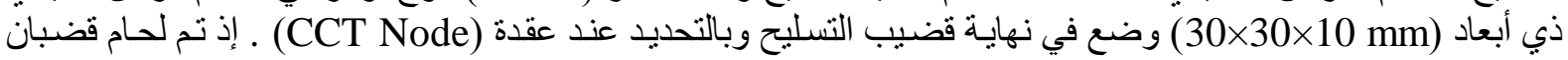
بقر (6mm) على جانبي قضيب التسليح لتساعد في تمركز القضيب في منتصف العتبة والثكل (2) يوضح ذللك.

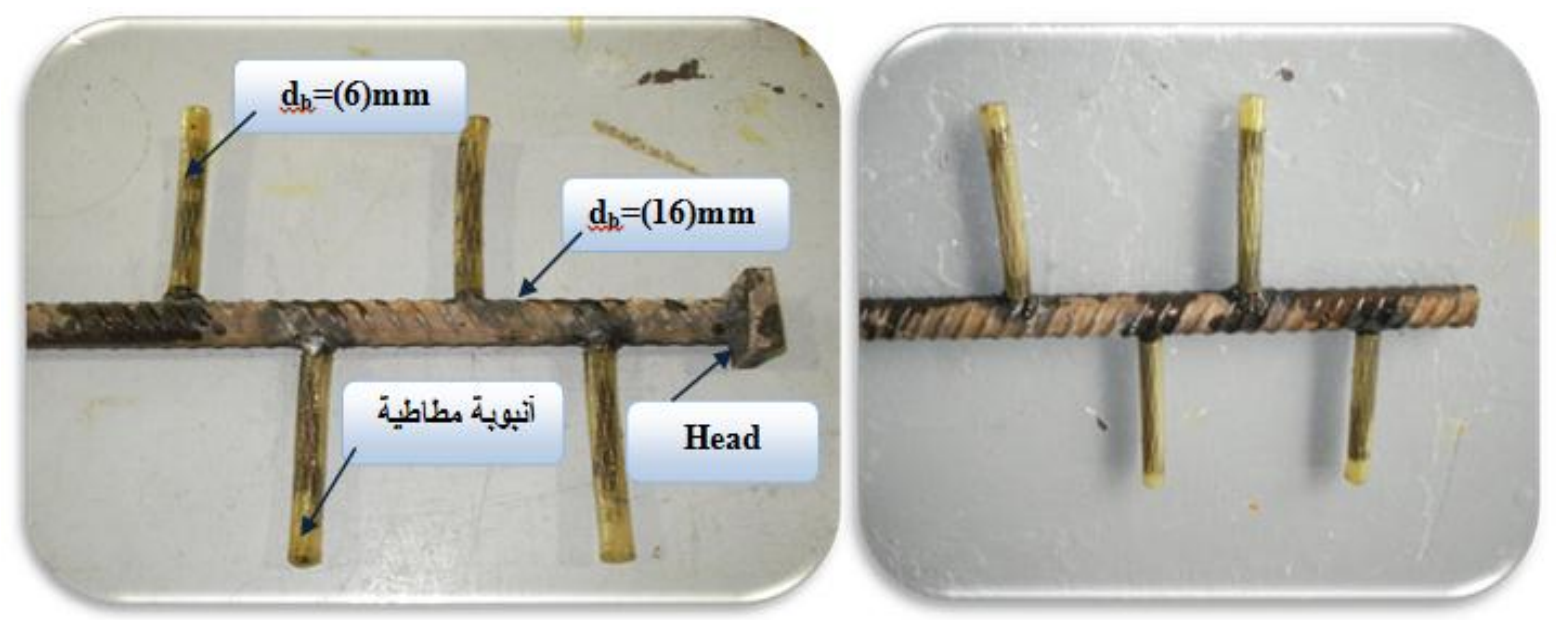

الثكل (2): يوضح الهيكل الحديدي بنوعيه ذات التسليح المدعم وغير المدعم بالر أس الفولاذي والمستخدم في العتبات الخرسانية. 


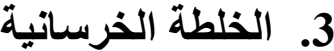

تم اختيار المقاومة التصميمية للخلطة الخرسانية المستخدمة في صب العتبات الخرسانية بحدود (37MPa) عند عمر(28)

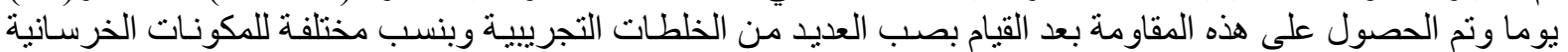

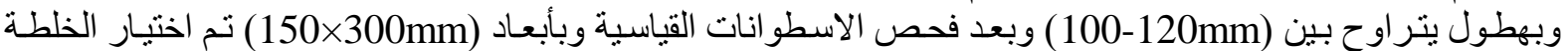

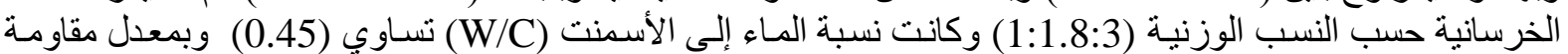
انضغاط (37MPa) بعمر(28) يو ما وبمعدل هطول (100mm). و هي الخلطة المعتمدة في هذا البحث.

\section{4. تحضير النماذج}

واستخدم نموذج خرسـاني بطول (700mm) و عرض (150mm) وارتفاع (200mm)، تم إعداد (24) عنبـة خرسانية

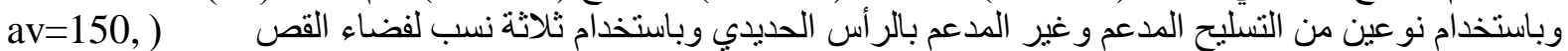

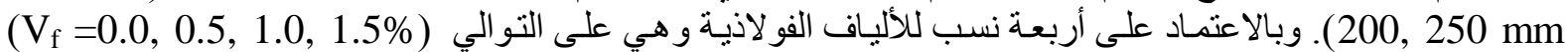

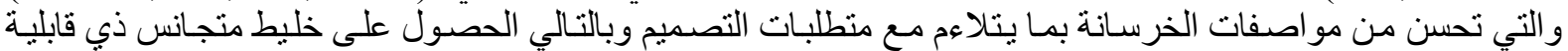

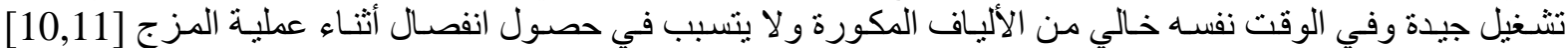

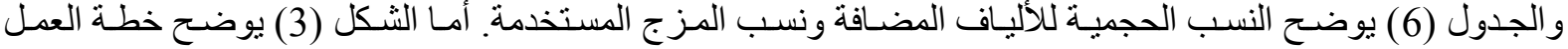
و المتغير ات المعتمدة لصب تللك النماذج.

الجدول (6): يوضح النسب الحجمية للألياف ونسب المزج المستخدمة

\begin{tabular}{|c|c|c|c|}
\hline النسب الحجمية للألياف & 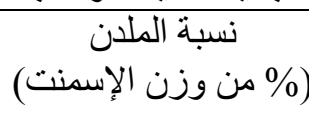 & النسبة الوزنية للمزيج & رمز الخلطة \\
\hline 0.0 & 0.0 & $1: 1.8: 3 / 0.45$ & $\mathrm{M}(0-0)$ \\
\hline 0.5 & 0.2 & $1: 1.8: 3 / 0.45$ & $\mathrm{M}(0.5-0.2)$ \\
\hline 1.0 & 0.45 & $1: 1.8: 3 / 0.45$ & $\mathrm{M}(1.0-0.45)$ \\
\hline 1.5 & 0.95 & 1:1.8:3/0.45 & $\mathrm{M}(1.5-0.95)$ \\
\hline
\end{tabular}

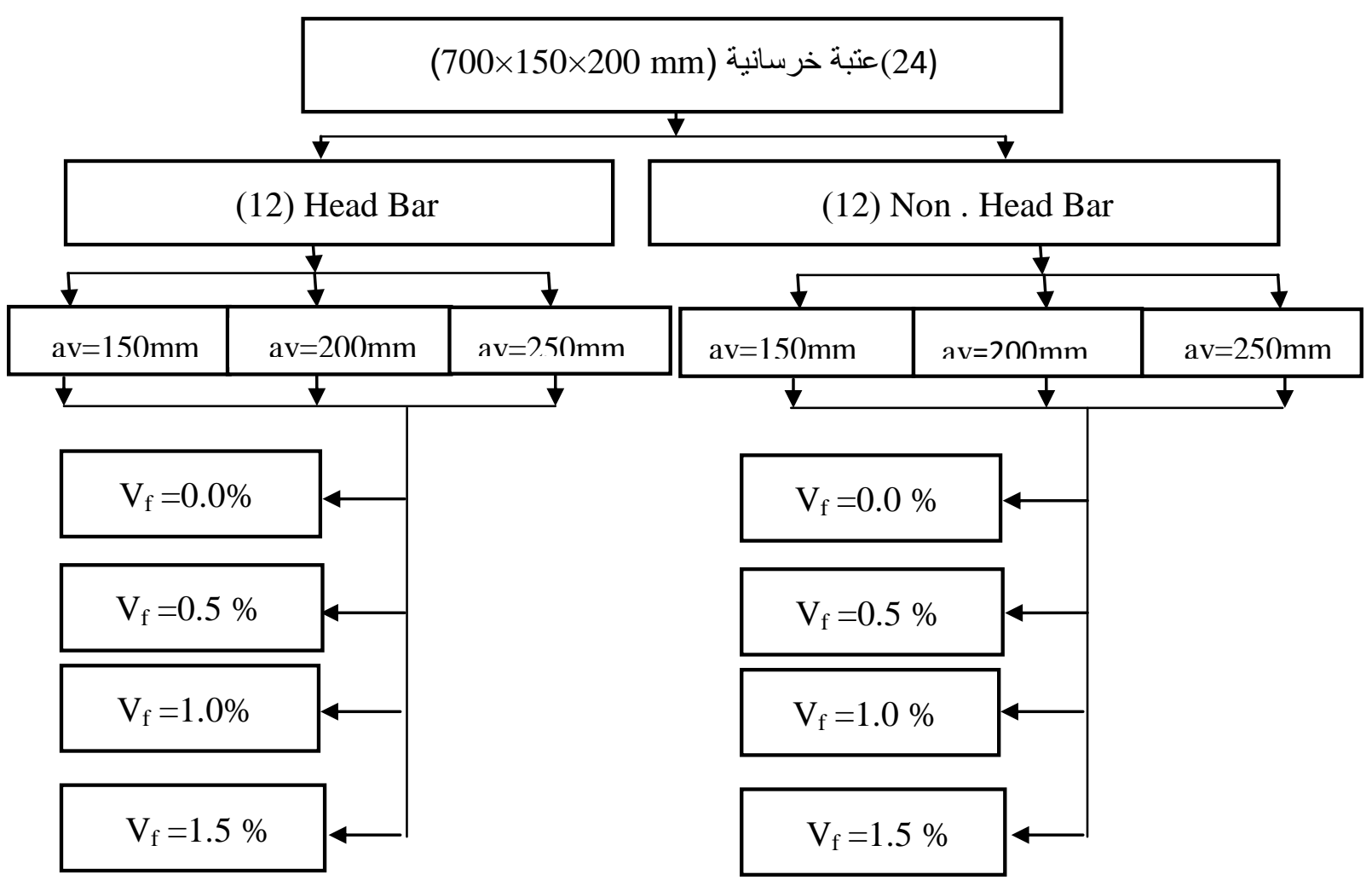

الثكل (3): يوضح مخططاً للمتغيرات المعتمدة لنماذج التثبيت باستخدام قضيب تسليح بقطر (16 mm) وبنوعين من التسليح المدعم وغير المدعم بالرأس الحديدي. 


\section{5. الفحوصات المعتمدة في البحث}

Universal )

1- فحص قابلية التحمل للعتبات الخرسانية باستخدام جهاز فحص هيدروليكي

(500kN) ذو سعة قدر ها (Testing Machine

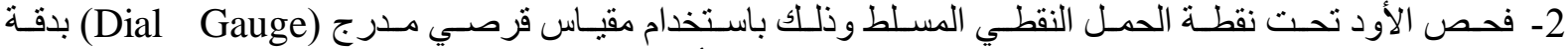

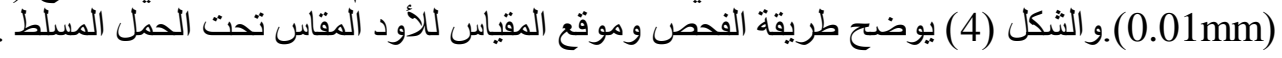

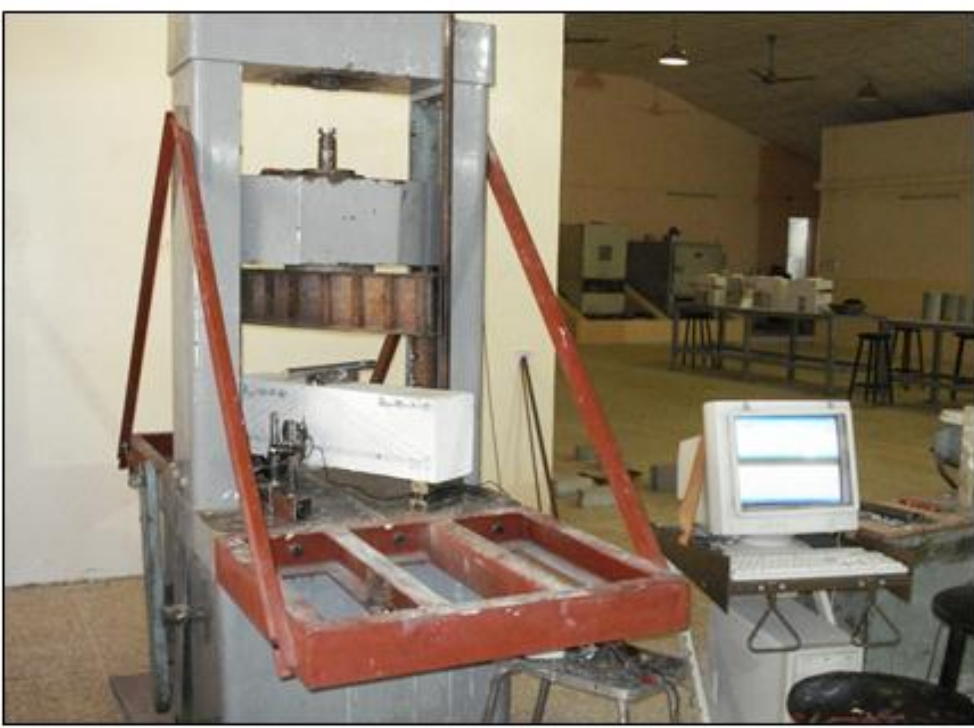

الثكل (4): يوضح طريقة الفحص للعتبات الخرسانية

6. - النتائج والمناقشة

وشملت كل من:

1.6 : دراسة سلوكية التسليح بالقضبان المدعمة بالر أس الحديدي على قابلية التحمل للعتبات الخرسانية واستجابتها مع

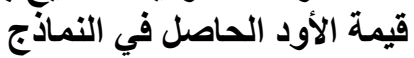

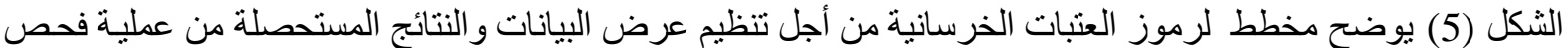

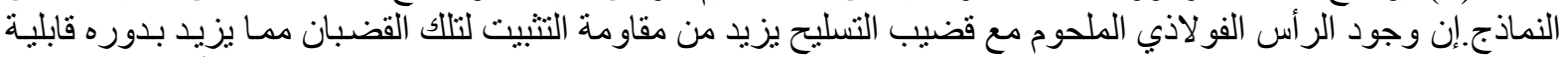

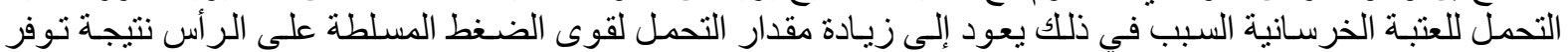

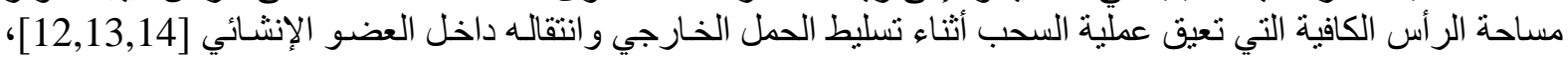

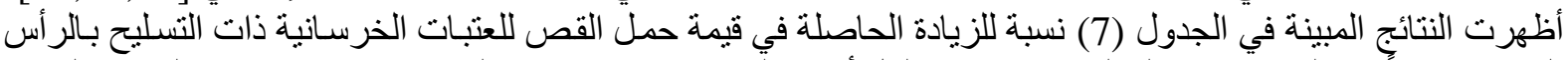

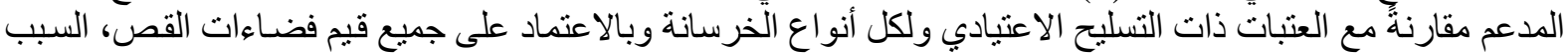

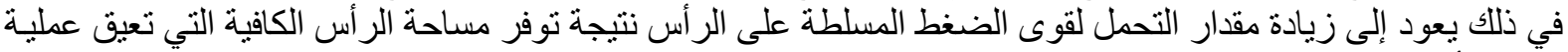
السحب أثناء تسليط الحمل الخارجي و انتقاله داخل العضو الإنطا لإنشائي .

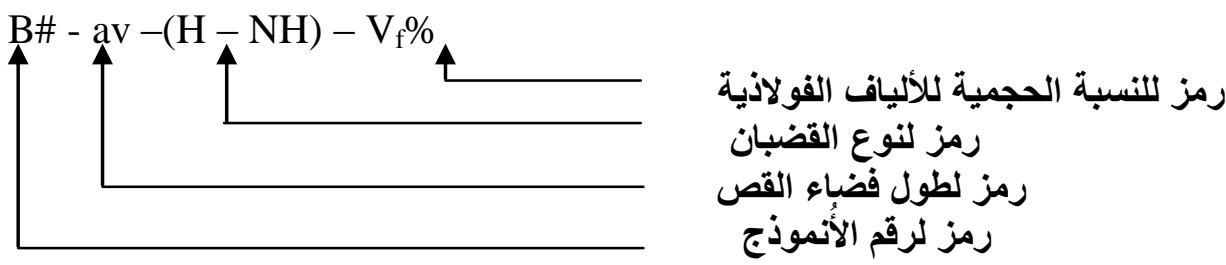

الثكل (5): يوضح ترميز للعتبات الخرسانية المستخدمة. 
الجدول (7): يوضح نسبة الزيادة الحاصلة في حمل القص للعتبات الخرسانية ذات التسليح المدعم بالرأس الفولاذي مقارنةً بالعتبات ذات التسليح غير المدعم بالر أس الفولاذي.

\begin{tabular}{|c|c|c|c|c|c|}
\hline Beam & $\begin{array}{c}\text { av } \\
(\mathbf{m m})\end{array}$ & $\begin{array}{l}\text { Reinforcement } \\
\text { configuration }\end{array}$ & $\begin{array}{c}\text { Failure } \\
\operatorname{Load}(k N)\end{array}$ & $\begin{array}{c}\text { \% Increase } \\
\text { in failure } \\
\text { Load }\end{array}$ & Mode of failure \\
\hline B1-150-N.H-0.0 & \multirow[t]{2}{*}{150} & Non.Head & 140 & \multirow[t]{2}{*}{39} & Sudden Shear \\
\hline B2-150- H-0.0 & & Head & 195 & & Sudden Shear \\
\hline B3-200-N.H-0.0 & \multirow[t]{2}{*}{200} & Non.Head & 95 & \multirow[t]{2}{*}{58} & Sudden Shear \\
\hline B4-200 -H-0.0 & & Head & 150.5 & & Sudden Shear \\
\hline B5-250-N.H-0.0 & \multirow[t]{2}{*}{250} & Non.Head & 93 & \multirow[t]{2}{*}{73} & Sudden Shear \\
\hline B6-250- H-0.0 & & Head & 161 & & Sudden Shear \\
\hline B7-150-N.H-0.5 & \multirow[t]{2}{*}{150} & Non.Head & 140 & \multirow[t]{2}{*}{63} & Shear \\
\hline B8-150-H-0.5 & & Head & 228 & & Shear \\
\hline B9-200-N.H-0.5 & \multirow[t]{2}{*}{200} & Non.Head & 109 & \multirow[t]{2}{*}{42} & Shear \\
\hline B10-200- H- 0.5 & & Head & 155 & & Shear \\
\hline B11-250-N.H- & \multirow[t]{2}{*}{250} & Non.Head & 101 & \multirow[t]{2}{*}{63} & Shear \\
\hline B12-250- H-0.5 & & Head & 165 & & Shear \\
\hline B13-150-N.H- & \multirow[t]{2}{*}{150} & Non.Head & 145 & \multirow[t]{2}{*}{59} & Shear \\
\hline B14-150- H-1.0 & & Head & 230 & & Shear \\
\hline B15-200-N.H- & \multirow[t]{2}{*}{200} & Non.Head & 124 & \multirow[t]{2}{*}{40} & Shear \\
\hline B16-200- H-1.0 & & Head & 173 & & Shear \\
\hline B17-250-N.H- & \multirow[t]{2}{*}{250} & Non.Head & 110 & \multirow[t]{2}{*}{50} & Shear \\
\hline B18-250- H-1.0 & & Head & 165 & & Sudden Shear \\
\hline B19-150-N.H- & \multirow[t]{2}{*}{150} & Non.Head & 151 & \multirow[t]{2}{*}{75} & Shear \\
\hline B20 -150- H-1.5 & & Head & 265 & & Shear \\
\hline B21-200-N.H- & \multirow[t]{2}{*}{200} & Non.Head & 150 & \multirow[t]{2}{*}{30} & Shear \\
\hline B22-200- H-1.5 & & Head & 195 & & Shear \\
\hline B23-250-N.H- & \multirow[t]{2}{*}{250} & Non.Head & 125 & \multirow[t]{2}{*}{36} & Shear \\
\hline B24-250- H-1.5 & & Head & 170 & & Shear \\
\hline
\end{tabular}

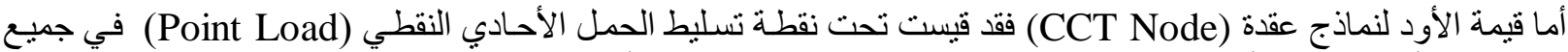

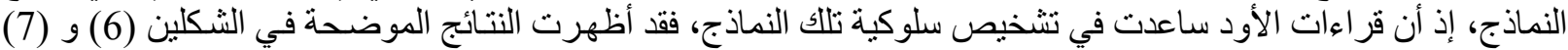

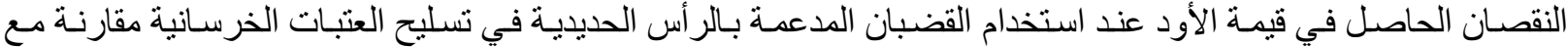

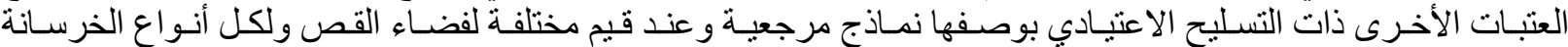

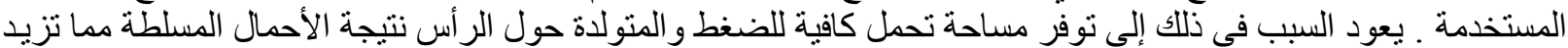
من تحمل العتبة وبالتالي تقلل من الأود الحاصل في تللك العتبات. 

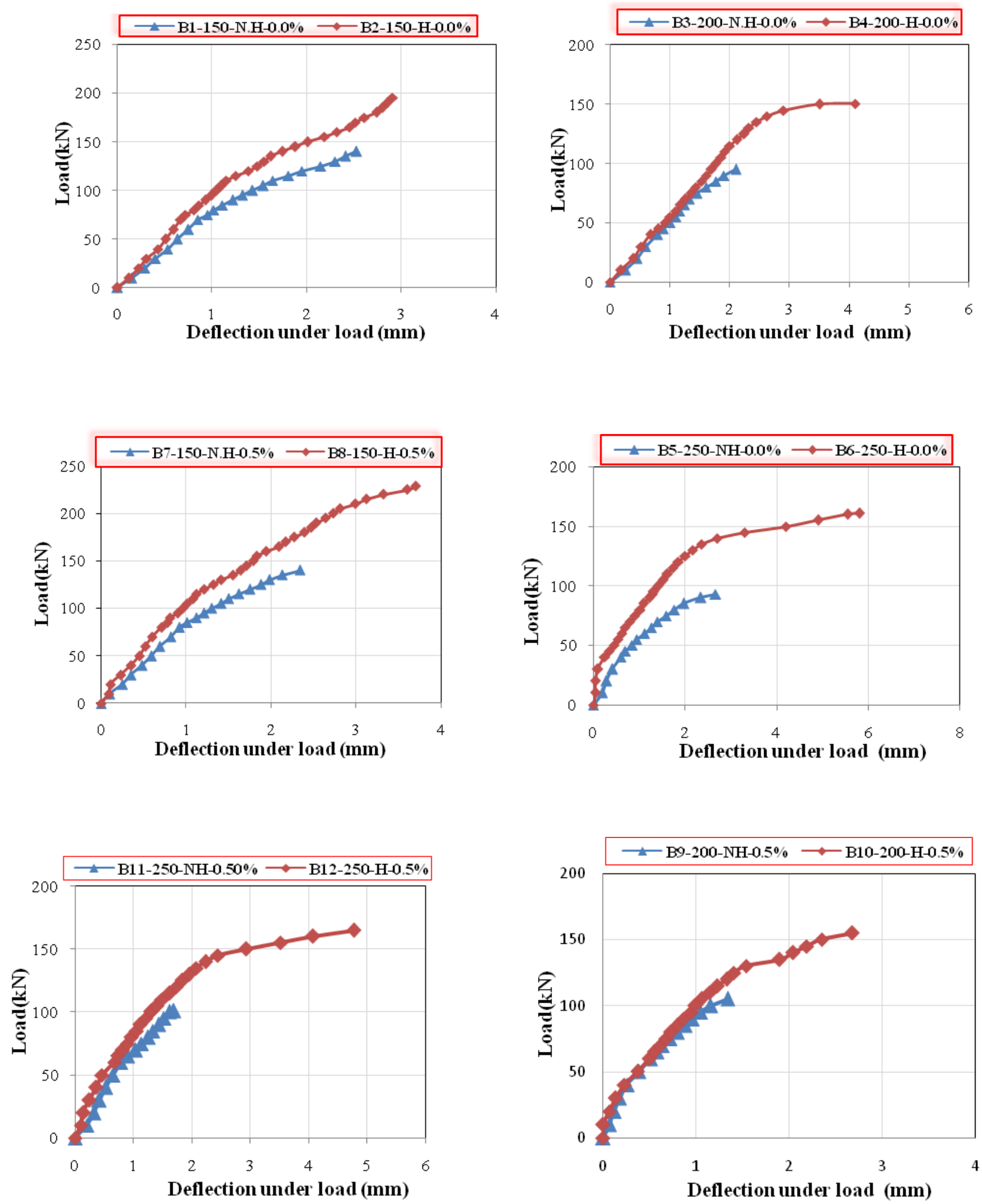

الثكل (6): يوضح منحني علاقة (الحمل - الأود) للعتبات الخرسانية عند (Vf=0.0 0.5\%) وعند فضاءات قص مختلفة ولنوعين من التسليح المدعم وغير المدعم بالرأس الحديدي (H , N.H) 

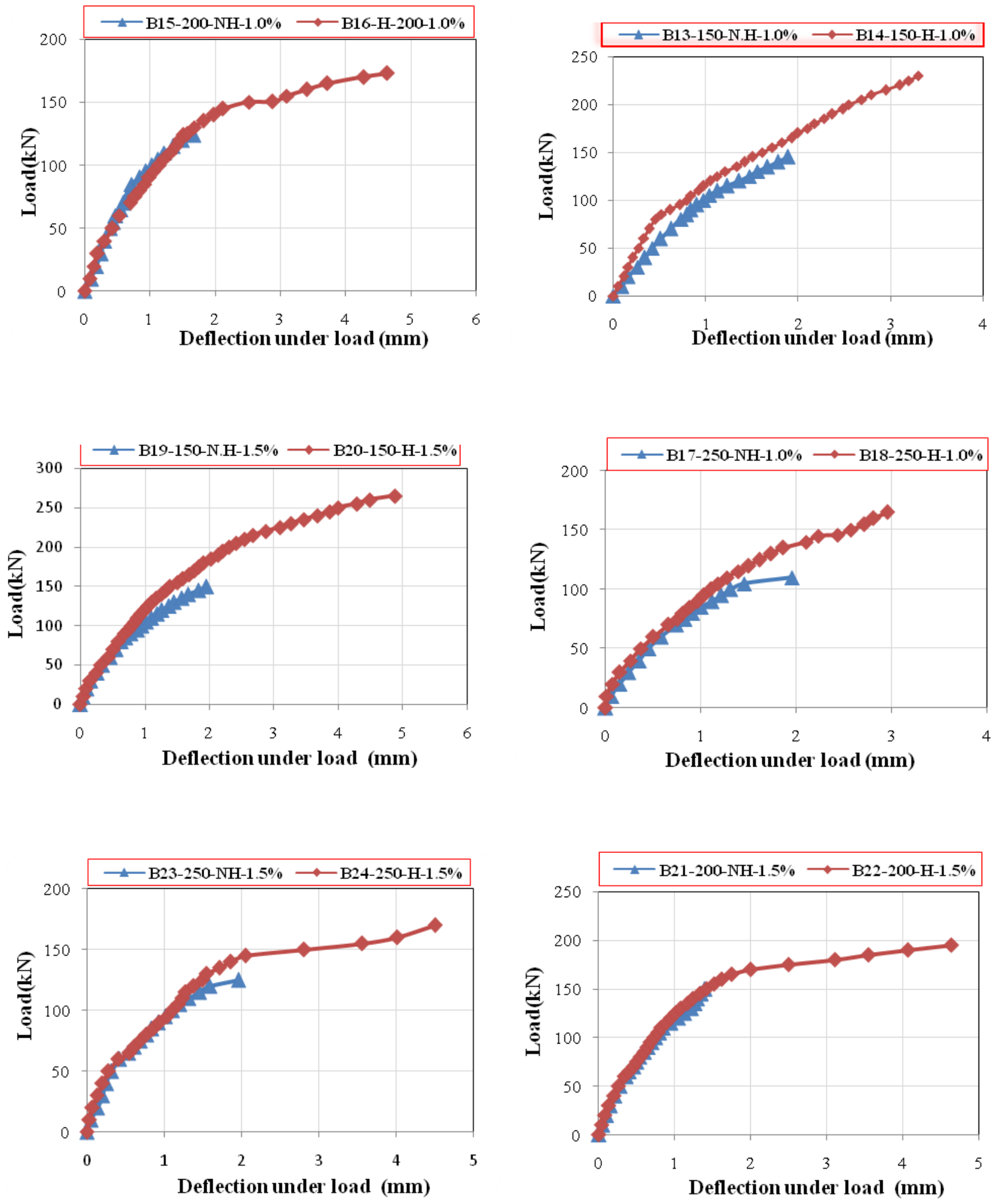

الثكل (7): يوضح منحني علاقة (الحمل - الأود) للعتبات الخرسانية عند (V)=1.0 1.5\%) وعند فضاءعاءات قص مختلفة ولنوعين من التسليح المدعم وغير المدعم بالرأس الحديدي (H , N.H) 
2.6: تأثير الر أس الحديدي على سلوكية التشقق للعتبات الخرساتية المفحوصة

جميع النماذج فثلت بواسطة القص حيث ظهر التشقق الأول تحت الحمل أي عند نقطة أعلى عزم ثم يظهر التشقق الثاني

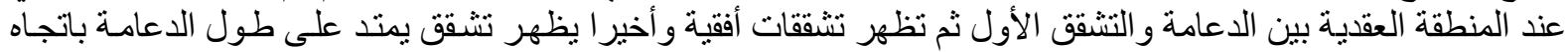

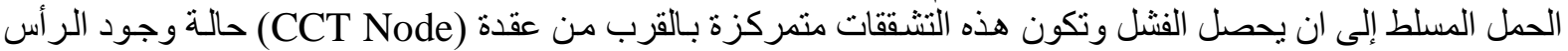

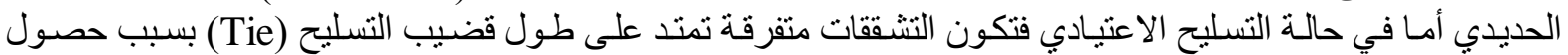

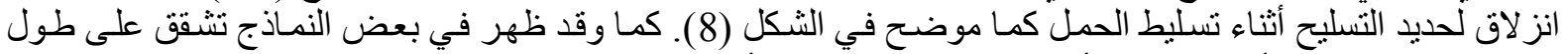

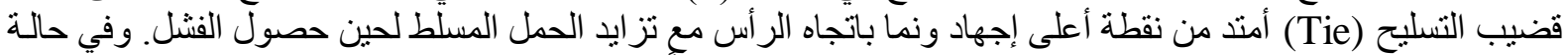

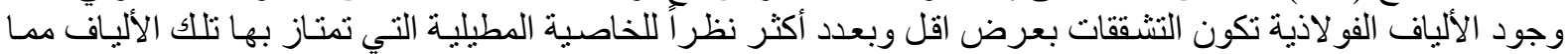

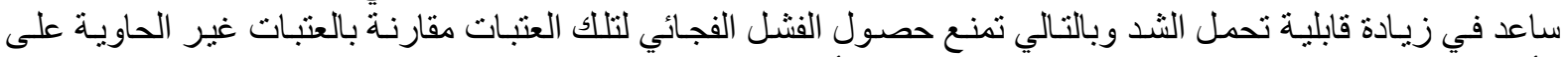
الألياف الفو لاذية [15,16] و الثكل (10) يوضح بعض أشكال الفشل الحاصلة في العتبات الخرسانية المستخدمة في البحث
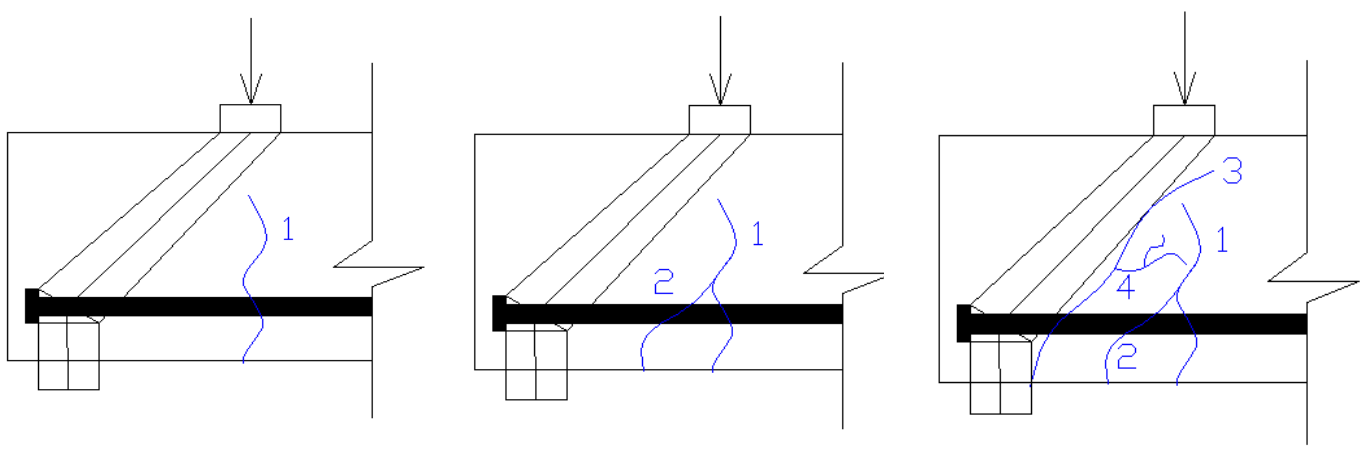

الثكل (8): يوضح مراحل التشقق للعتبات الخرسانية المسلحة

\section{6: دراسة تأثير إضافة الألياف الفولاذية على قابلية تحمل العتبات الخرسانية}

إن عملية إضـافة الألياف الفو لاذيـة تكسب العتبـة الخرسـانية قوى إضـافية لتحمل قوى القص و الناتجـة عن الأحمـال

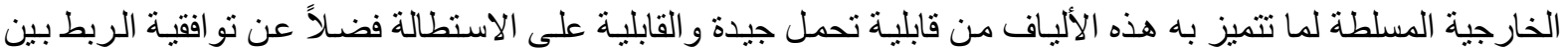

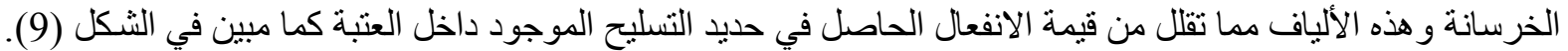

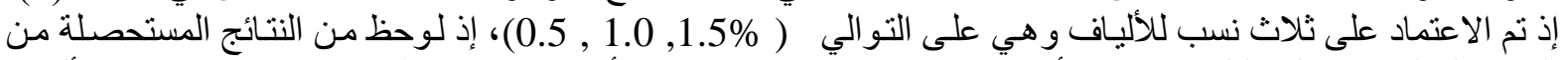

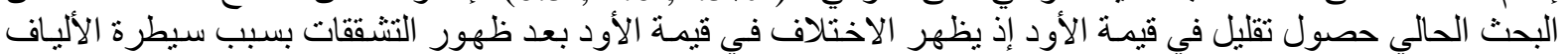

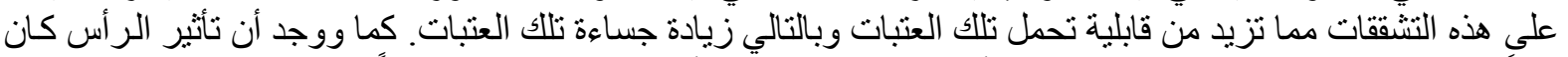

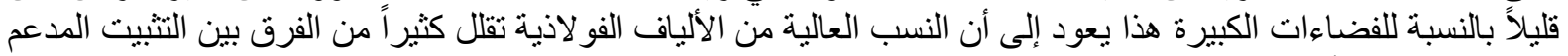

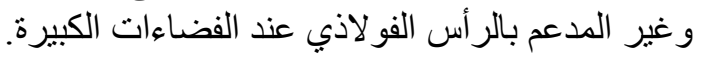

و الجدول (8) يوضح نسبة الزيادة الحاصلة في حمل القص النهائي نتيجة زيادة نسبة الإضـافة الحجمية للألياف الفو لاذيـة.

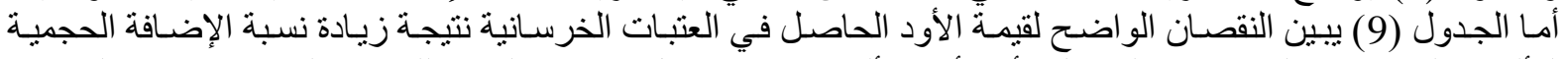

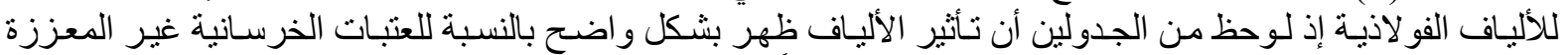

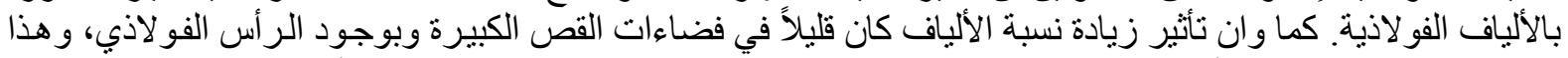

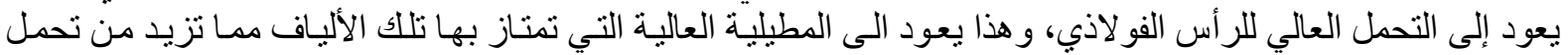



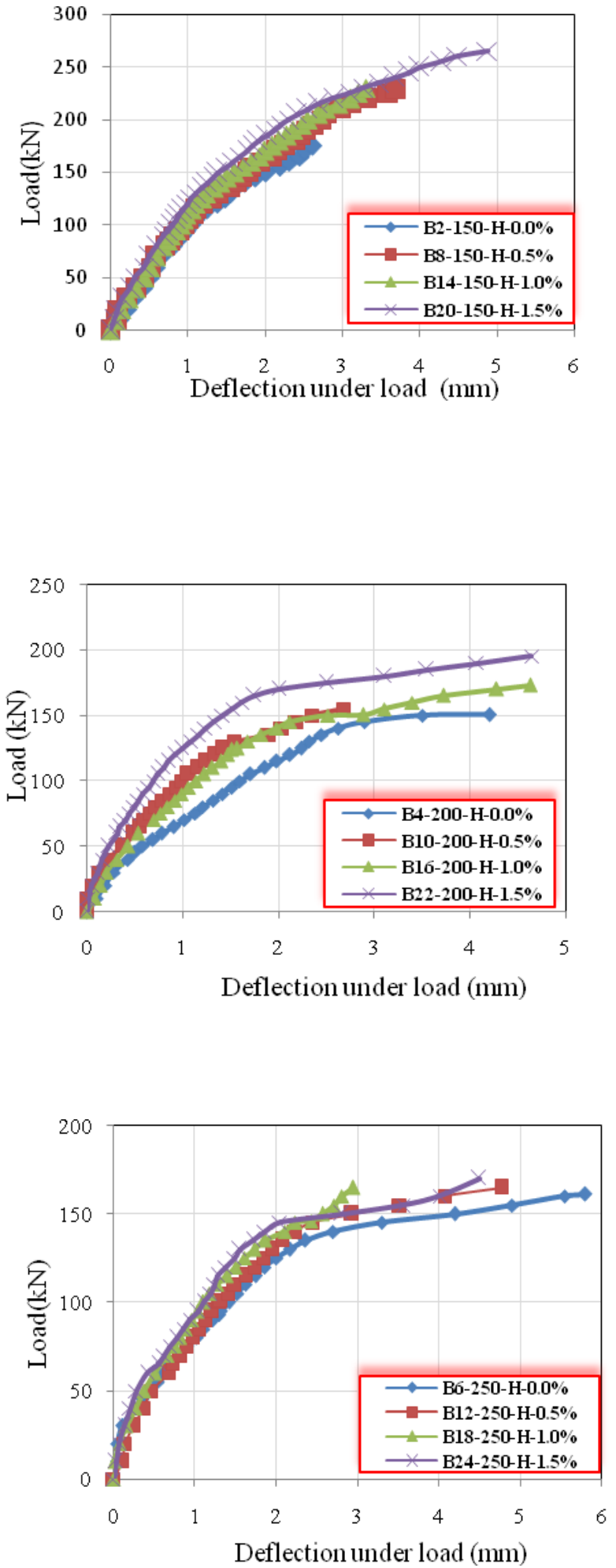
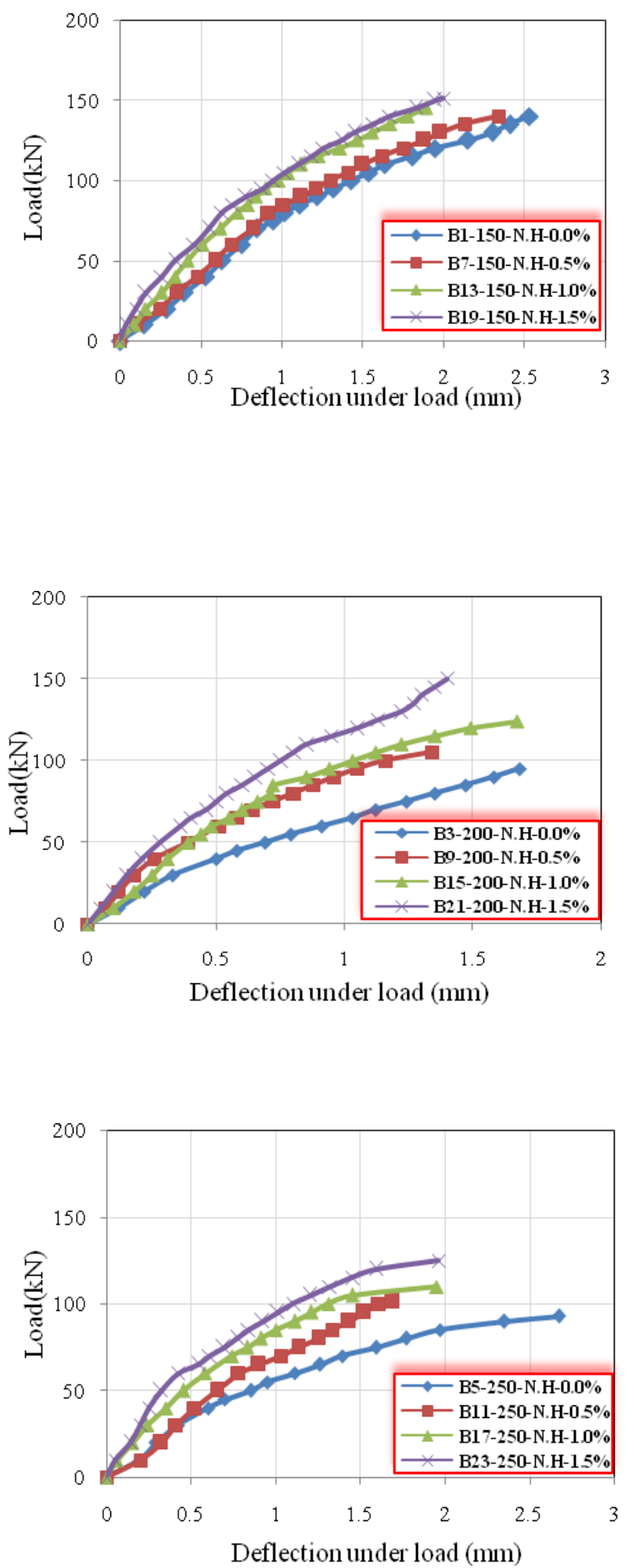

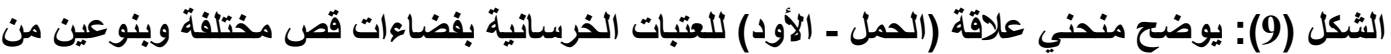
التسليح المدعم وغير المدعم بالرأس الفولاذي وعند أربعة نسب من الألياف الفولانية المضافة الفافية

$$
\text { (Vf = 0.0, 0.5, 1.0, 1.5 \%) }
$$
}


ألسليفاني: سلوك ومقاومة عقد (الانضغاط ـ الانضغاط ـ الثد) المثبتة بقضبان منتهية الروؤس في العتبات

الجدول (8): يوضح مقدار الأود الحاصل عند الفثل للعتبات الخرسانية ومقدار الزيادة في حمل القص عند نسب مختلفة للألياف الفولاذية

\begin{tabular}{|c|c|c|c|c|c|}
\hline Beam & $\mathbf{V}_{\mathrm{f}} \%$ & $\begin{array}{l}\text { Reinf. } \\
\text { Config. }\end{array}$ & $\begin{array}{l}\text { Deflection } \\
\text { (mm) }\end{array}$ & $\begin{array}{c}\text { Load } \\
(k N)\end{array}$ & $\begin{array}{c}\text { \%Increase } \\
\text { of load }\end{array}$ \\
\hline B1-150-N.H-0.0 & 0.0 & No Head & 2.53 & 140 & - \\
\hline B7-150-N. H-0.5 & 0.5 & No Head & 2.34 & 140 & - \\
\hline B13-150-N. H-1.0 & 1.0 & No Head & 1.89 & 145 & 4 \\
\hline B19-150-N. H-1.5 & 1.5 & No Head & 2 & 151 & 8 \\
\hline B2-150- H-0.0 & 0.0 & Head & 2.91 & 195 & - \\
\hline B8-150- H- 0.5 & 0.5 & Head & 3.7 & 228.5 & 17 \\
\hline B14-150- H-1.0 & 1.0 & Head & 3.3 & 230 & 18 \\
\hline B20-150- H-1.5 & 1.5 & Head & 4.88 & 265 & 36 \\
\hline B3-200-N.H-0.0 & 0.0 & No Head & 1.67 & 95 & - \\
\hline B9-200-N. H-0.5 & 0.5 & No Head & 1.34 & 105 & 11 \\
\hline B15-200-N. H-1.0 & 1.0 & No Head & 1.67 & 124 & 31 \\
\hline B21-200-N. H-1.5 & 1.5 & No Head & 1.4 & 150 & 58 \\
\hline B4-200- H-0.0 & 0.0 & Head & 4.2 & 150.50 & - \\
\hline B10-200- H- 0.5 & 0.5 & Head & 2.68 & 155 & 3 \\
\hline B16-200- H-1.0 & 1.0 & Head & 4.76 & 173 & 15 \\
\hline B22-200- H -1.5 & 1.5 & Head & 4.76 & 195 & 30 \\
\hline B5-250-N. H-0.0 & 0.0 & No Head & 2.67 & 93 & - \\
\hline B11-250-N. H-0.5 & 0.5 & No Head & 1.69 & 101 & 9 \\
\hline B17-250-N. H-1.0 & 1.0 & No Head & 1.95 & 110 & 18 \\
\hline B23-250-N. H-1.5 & 1.5 & No Head & 1.96 & 125 & 34 \\
\hline B6-250-H-0.0 & 0.0 & Head & 5.8 & 161 & - \\
\hline B12-250- H- 0.5 & 0.5 & Head & 4.77 & 165 & 2 \\
\hline B18-250- H-1.0 & 1.0 & Head & 2.95 & 165 & 2 \\
\hline B24-250- H-1.5 & 1.5 & Head & 4.5 & 170 & 6 \\
\hline
\end{tabular}


الجدول (9): يوضح مقار النقصان الحاصل في قيمة الأود للعتبات الخرسانية المسلحة بالألياف الفولاذية وعند حمل بالياف ثابت والمتمثل بحمل الفثل للعتبات غير المسلحة بات بالألياف

\begin{tabular}{|c|c|c|c|c|c|}
\hline Beam & $\mathbf{V}_{\mathrm{f}} \%$ & $\begin{array}{l}\text { Reinforcement } \\
\text { configuration }\end{array}$ & $\begin{array}{r}\text { Load } \\
(\mathbf{k N})\end{array}$ & deflection & $\begin{array}{c}\text { \%Decrease of } \\
\text { deflection }\end{array}$ \\
\hline B1-150-N.H-0.0 & 0.0 & No Head & \multirow[t]{4}{*}{140} & 2.5 & - \\
\hline B7-150-N. H-0.5 & 0.5 & No Head & & 2.3 & 8 \\
\hline B13-150-N. H- & 1.0 & No Head & & 1.8 & 28 \\
\hline B19-150-N. H- & 1.5 & No Head & & 1.7 & 32 \\
\hline B2-150- H-0.0 & 0.0 & Head & \multirow[t]{4}{*}{195} & 2.9 & - \\
\hline B8-150- H-0.5 & 0.5 & Head & & 2.6 & 10 \\
\hline B14-150- H-1.0 & 1.0 & Head & & 2.5 & 14 \\
\hline B20-150- H-1.5 & 1.5 & Head & & 2.2 & 24 \\
\hline B3-200-N.H-0.0 & 0.0 & No Head & \multirow[t]{4}{*}{95} & 2.1 & - \\
\hline B9-200-N. H-0.5 & 0.5 & No Head & & 1.1 & 48 \\
\hline B15-200-N. H- & 1.0 & No Head & & 0.9 & 57 \\
\hline B21-200-N. H- & 1.5 & No Head & & 0.6 & 71 \\
\hline B4-200- H-0.0 & 0.0 & Head & \multirow[t]{4}{*}{150.5} & 4.2 & - \\
\hline B10-200- H-0.5 & 0.5 & Head & & 2.4 & 43 \\
\hline B16-200- H-1.0 & 1.0 & Head & & 2.6 & 38 \\
\hline B22-200- H - 1.5 & 1.5 & Head & & 1.5 & 64 \\
\hline B5-250-N. H-0.0 & 0.0 & No Head & \multirow[t]{4}{*}{93} & 2.7 & - \\
\hline B11-250-N. H- & 0.5 & No Head & & 1.5 & 44 \\
\hline B17-250-N. H- & 1.0 & No Head & & 1.2 & 56 \\
\hline B23-250-N. H- & 1.5 & No Head & & 1.0 & 63 \\
\hline B6-250-H-0.0 & 0.0 & Head & \multirow[t]{4}{*}{161} & 5.8 & - \\
\hline B12-250- H-0.5 & 0.5 & Head & & 4.2 & 28 \\
\hline B18-250- H-1.0 & 1.0 & Head & & 2.8 & 51 \\
\hline B24-250- H-1.5 & 1.5 & Head & & 4.1 & 29 \\
\hline
\end{tabular}




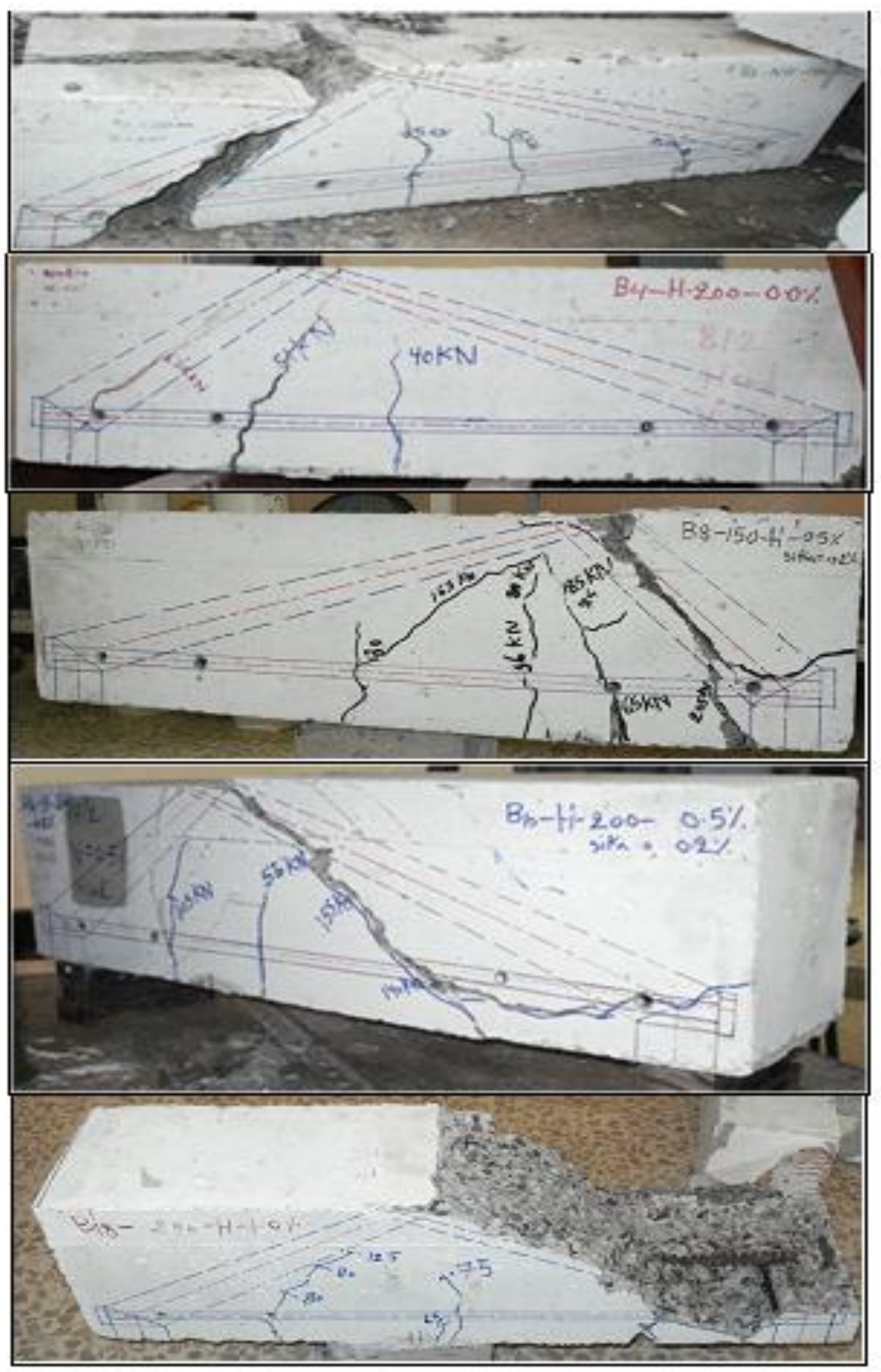

الثكل (10): يوضح نماذج لأثكال الفثل الحاصلة للعتبات الخرسانية المستخدة في البحث 
4.6: دراسة تأثير إضافة الألياف الفولاذية على جساوة ومطيلية ومتانة العتبات الخرسانية

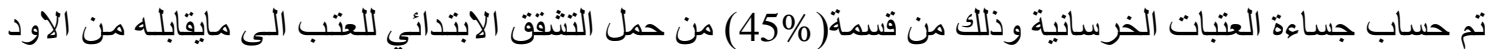

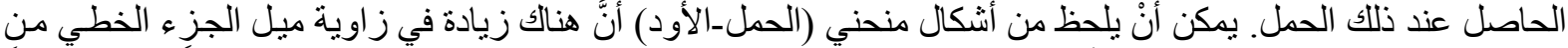

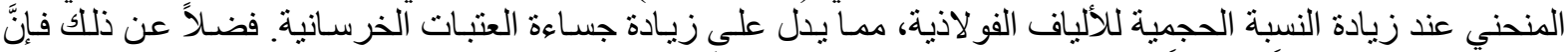

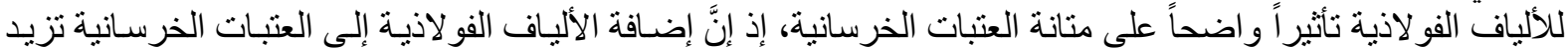

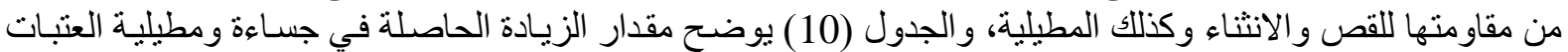

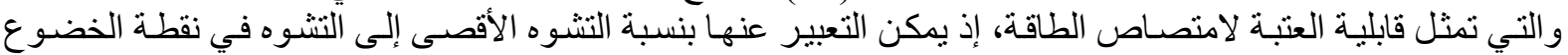

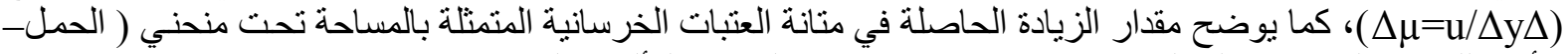
الأود) للعتبات الخرسانية المسلحة نتيجة زيادة نسبة الإضافة الحجمية للألياف الفو لاذية [17].

الجدول (10): يوضح نسب الزيادة في جساعة ومطيلية ومتانة العتبات الخرسانية بزيادة نسبة الإضافة الحجمية للألياف الفولاذية

\begin{tabular}{|l|c|c|c|c|c|}
\hline \multicolumn{1}{|c|}{ Beam } & $\begin{array}{c}\text { Stiffness } \\
(\mathrm{kN} / \mathrm{mm})\end{array}$ & $\begin{array}{c}\% \\
\text { Increase } \\
\text { of } \\
\text { stiffness }\end{array}$ & $\begin{array}{c}\text { Ductility } \\
\mu\end{array}$ & $\begin{array}{c}\% \\
\text { Increase } \\
\text { of } \Delta \mu\end{array}$ & $\begin{array}{c}\text { Toughness } \\
\text { (Area Under } \\
\text { Curve }) \\
(\mathrm{kN} . \mathrm{mm})\end{array}$ \\
\hline B1-150-N.H-0.0 & 80.8 & - & 2.07 & - & 203.8 \\
\hline B7-150-N. H-0.5 & 87.5 & 8 & 2.09 & 1 & 194.4 \\
\hline B13-150-N. H-1.0 & 115 & 42 & 2.25 & 9 & 210.1 \\
\hline B19-150-N. H-1.5 & 127.8 & 58 & 3.17 & 53 & 251.5 \\
\hline B2-150- H-0.0 & 97.7 & - & 2.53 & - & 478.4 \\
\hline B8-150- H-0.5 & 104.1 & 7 & 2.62 & 4 & 566.2 \\
\hline B14-150- H-1.0 & 110.3 & 13 & 3.58 & 42 & 486.7 \\
\hline B20-150- H-1.5 & 120.3 & 23 & 3.87 & 53 & 996.3 \\
\hline B3-200-N.H-0.0 & 78.5 & - & 2.13 & - & 117.7 \\
\hline B9-200-N. H-0.5 & 124.3 & 58 & 2.62 & 23 & 95 \\
\hline B15-200-N. H-1.0 & 127.3 & 62 & 2.67 & 26 & 130.1 \\
\hline B21-200-N. H-1.5 & 156.9 & 99 & 3.62 & 70 & 132 \\
\hline B4-200- H-0.0 & 70.6 & - & 2.27 & - & 477.2 \\
\hline B10-200- H-0.5 & 87.18 & 23 & 2.36 & 4 & 283.6 \\
\hline B16-200- H-1.0 & 97.3 & 38 & 2.38 & 5 & 588.6 \\
\hline B22-200- H -1.5 & 141.5 & 100 & 3.31 & 46 & 686.6 \\
\hline B5-250-N. H-0.0 & 69.8 & - & 2.14 & - & 162.6 \\
\hline B11-250-N. H-0.5 & 82.6 & 18 & 2.16 & 1 & 100 \\
\hline B17-250-N. H-1.0 & 110 & 58 & 2.46 & 15 & 144.4 \\
\hline B23-250-N. H-1.5 & 137 & 96 & 2.85 & 33 & 162.7 \\
\hline B6-250-H-0.0 & 85.2 & - & 2.46 & - & 704.2 \\
\hline B12-250- H-0.5 & 92.8 & 9 & 2.73 & 11 & 646.9 \\
\hline B18-250- H-1.0 & 123.8 & 45 & 3 & 22 & 354.5 \\
\hline B24-250- H-1.5 & 127.5 & 50 & 3.6 & 46 & 700 \\
\hline & & & & & \\
\hline
\end{tabular}


7. الاستنتاجات

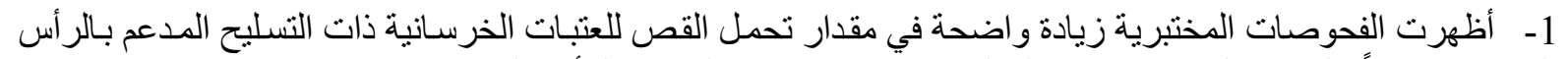

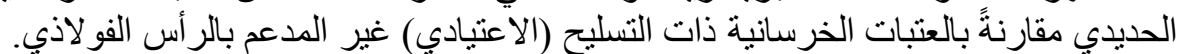

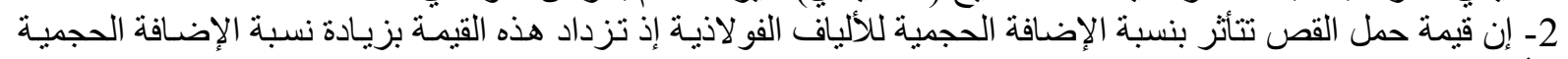
لكألياف المضافة.

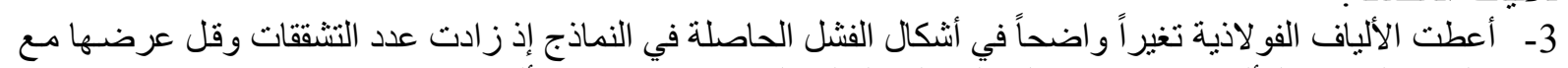

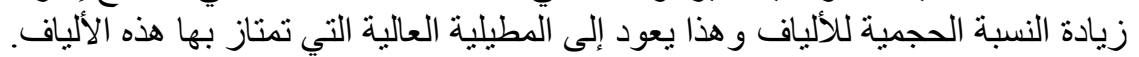

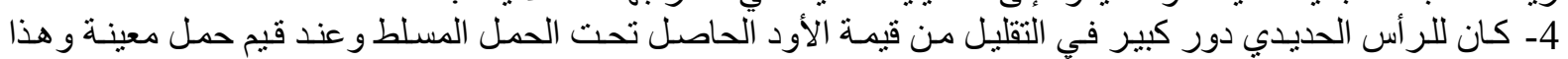

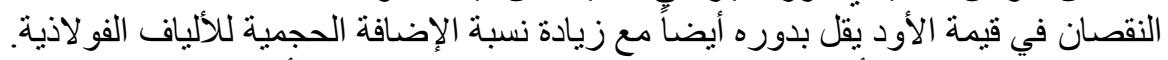

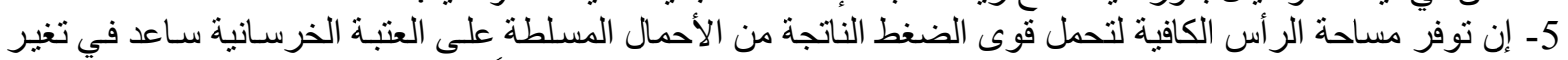

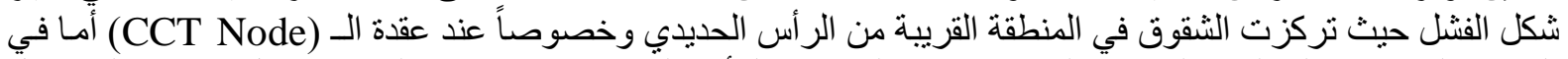
العتبات الخرسانية المسلحة بالقضبان المستقيمة غير المدعمة بالر أس الفو لاذي فقد ظهرت الثراً الثقوق بشكل متفرق على طول 6ضيب التسليح. 6- كان للألياف الفو لاذية دور مهم وفعال في زيادة جساءة ومطيلية ومتانة العتبات الخرسانية المسلحة بالألياف الفو لاذيـة.

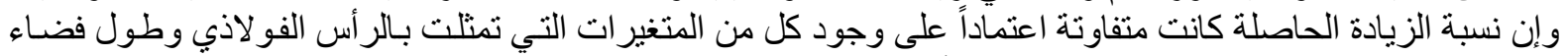
القص وكذللك النسبة المئوية للإضافة الحجمية للألياف الفو لاذية.

\section{References}

[1] ACI Committee (318-08), Building Code Requirements for Structural Concrete (ACI 318-08) and Commentary (ACI 318-08), American Concrete Institute, 2008, 471 pp.

[2] Thompson, M.K., Klingner, R.E., Jirsa, J.O., and Breen, J.E., "Anchorage Behavior of Headed Reinforcement: Literature Review", Centre for Transportation Research, The University of Texas at Austin, Report 1855-1, May, 2002, pp. 1-102.

[3] Thompson, M.K., Ledesma, A.L., Jirsa, J.O., Breen, J.E., and Klingner, R.E., “Anchorage Behavior of Headed Reinforcement, Part A: Lap Splices, Part B: Design Provisions and Summary", Research Report 1855-3, May, 2002, pp. 1-104.

[4] Thompson, M.K., "The Anchorage Behavior of Headed Reinforcement in CCT Nodes and Lap Splices", PhD Dissertation, The University of Texas at Austin, May 2002, pp. 1502.

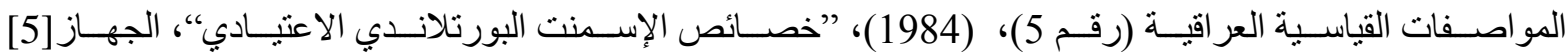
المركزي للتقييس و السيطرة النوعية، العراق، .1984 (1984)

[6] (BS 882 : 1983), "Aggregates from Natural Sources for Concrete", British Standards, Institute, London, 1983.

[7] (BS.882-1992), "Aggregates from Natural Source for Concrete", British Standard Institution, 1992.

[8] ACI committee 544.3R- 84, "Guide for Specifying, Mixing, Placing, and Finishing Steel Fiber Reinforced Concrete”, ACI journal, TITLE NO. 81-15, March-April, 1984, pp. 140148.

[9] ACI committee 212.2R-81, "Guide for use of Admixtures in Concrete", Concrete international, May, 1981.

[10] ACI committee 544, "State-of-the Art Report on Fiber Reinforced Concrete", ACI Journal, TITLE NO. 70-65, November 1973, pp . 729-742.

[11] ACI committee 544.3 R-93, "Guide for Specifying Proportioning Mixing, Placing, and, Finishing Steel Fiber Reinforced Concrete", American Concrete Institute, 1998, pp. 1-10.

[12] Thompson, M.K., Ziehl, M.J., Jirsa, J.O., and Breen, J.E., "CCT Nodes Anchored by Headed Bars Part 1 : Behavior of Nodes”, ACI Structural journal, TITLE NO. 102-S81, November -December, 2005. 
[13] Thompson, M.K., Jirsa, J.O., and Breen, J.E., "Behavior and Capacity of Headed Reinforcement", ACI Structural journal, TITLE NO. 103-S55, July-August, 2006, PP. 522530 .

[14] Thompson, M.K., Jirsa, J.O., and Breen, J.E., "CCT Nodes Anchored by Headed Bars Part 2: Capacity of Nodes”, ACI Structural journal, TITLE NO. 103-S08, JanuaryFebruary, 2006, PP. 65-73.

[15] Swamy, R.N., AL-Taan, S., and Ali, S.A.R., "Steel Fibers for Controlling Cracking and Deflection", Concrete international, August, 1979, pp. 41-49.

[16] Altun, F., Haktanir, T., Ari, K., "Effects of Steel Fiber Addition on Mechanical Properties of Concrete and RC beams", Construction and Building Materials 21, 2007, pp. 654-661.

[17] AL-Sulayfani, B.J., "Behavior of Steel Fibrous Concrete in Unaxial Compression", will be published in Journal of Al- Rafidain, VOL. 12, NO.4, 2003, pp. $42-51$. 